\title{
Source Case Investigation
}

National Cancer Institute

\section{Source}

National Cancer Institute. Source Case Investigation. NCI Thesaurus. Code C102713.

A public health activity for the determination of who transmitted a disease to another subject and whether this person: is still infectious; was reported to the health department as a disease case or suspect; or has infected others. 